\title{
Worker Recruiting with Favoritism and Bribery
}

\author{
Gen Chen 1,2 , Jun Tang2 \\ ${ }^{1}$ School of Economics \& Management, Wuhan University, Wuhan, China \\ ${ }^{2}$ School of Economics and Trade, Guangdong University of Finance and Economics, Guangzhou, China \\ Email: chgen001@sohu.com, juntang 77@163.com
}

Received 8 April 2015; accepted 23 June 2015; published 26 June 2015

Copyright (C) 2015 by authors and Scientific Research Publishing Inc.

This work is licensed under the Creative Commons Attribution International License (CC BY). http://creativecommons.org/licenses/by/4.0/

(c) () Open Access

\begin{abstract}
This paper discusses the corruptive action widespread in the organizations' worker recruiting: favoritism and bribery. The managers of the firm are actually able to discern the type of the productivity of the job-seekers, but they utilize the information advantage through the two types of misconduct-favoritism and bribery, at the expense of the profit share of the principal (the owner) and the workers' wage rent. The key conclusion is drawn from this paper as follows: neither the intensity of favoritism nor the wage level matters in determining whether there's profit or loss in the firm, whereas the key variable is the relative situation of exterior labor market.
\end{abstract}

\section{Keywords}

\section{Recruiting, Social Tie, Favoritism, Bribery}

\section{Introduction}

Modern firms usually separate the management right from the ownership, which causes the principal-agent problem due to the hidden action by the managers. In detail, the owners of firms usually delegate most daily operations, such as employee recruiting, to management [1] [2], which makes the principal \& agent problem inevitable. The uncertainty of the market condition makes the output volatile; therefore, the owner can't attribute the output level merely to the manager's merit or effort. But the payroll of the manager is usually supposed to depend directly on the output level, whose volatility brings risk to the manager's income, whereas one of the most important factors determining output is the workers' productivity; therefore, what workers the manager hires significantly impact the future bonus of the manager himself. In the labor market, the productivity of workers is quite heterogeneous, but manager is traditionally assumed to fail in directly discerning the details of the underlying qualifications of workers, and thus the signaling for jobs arises, e.g. education, certificate, which 
was first explored by Michael Spence in1973 [3].

Besides active signaling, the workers will also try to get favor from the manager to be hired, especially from those managers in charge of high-waged firms. What the candidates and the manager will do is an interest topic studied in many literatures (Breaugh J. A. \& Mary Starke [4]).

The function of social network in helping workers to be hired has been studied in some papers (Mark Grannovetter, 1988 [5]; Montgomery, 1991 [6]; Ioannides and Loury, 2004 [7]). The term "nepotism coefficient” was created by Goldberg [8] in 1982 to quantify the increase in the employer's utility caused by recruiting preferred workers. It's well known that, in China, managers or officials responsible for recruitment usually hire people with whom they have social ties (commonly called Guanxi in China), even if they are less productive (Tong Jun Wang et al., 2014 [9]). Moreover, abundant anecdotal evidence shows that nepotism is wide-spread in China, especially in the public sector like government, state-owned enterprises and other public sponsored agencies, whose principal-agent problem is rather severe (Elena Obukhova, 2012 [10]). The reason why the job applicants make use of the Guanxi is quite clear: if we are allowed to simply classify candidates into two categories, among which one type has high productivity and the other low, then the latter is strongly motivated to exploit the Guanxi to occupy the position that otherwise may belong to the highly productive candidates or even other low productive peers. Similarly, highly productive candidates are motivated to use Guanxi to compete against low productive candidates for the position. But there is still a question waiting for answers: what drives the manager to conduct favoritism (referred to the behavior of giving favor to connected persons in this article) in recruiting to some candidates with low productivity? There are various answers for the questions. According to the analysis of Carmichael (1988) [11], Friebel and Raith (2004) [12], managers responsible for selection may discretionally recruit low productive candidates because they fear being replaced by more productive candidates later. Prendergast \& Topel (1996) [13], and Levine et al. (2007) [14] have suggested that the manager hires the associated workers just because of his preference, which means the utility increase from favoring the connected candidates. Bramoullé and Goyal (2009) [15] have characterized favoritism as an exchange of favors (contracts or jobs) between members of the same group. They explicitly suppose that the exchange of favors within the group of interest can be repeated over time, which fails in explaining favoritism in one-shot games, as analyzed deeply by Michela Ponzo \& Vincenzo (2011) [16], where the manager hires an employee even though it is highly unlikely for the employees to be in the same or higher position to pay back the manager likewise later. This paper is enlightened largely by Canice Prendergast \& Robert H. Topel (1996) [13] and Michela Ponzo \& Vincenzo (2011) [16], but distinct from them in the following three ways.

1) The managers know the productivity of all candidates and the degree of social ties with him, and decide whether to hire a candidate or not based on the sign of the marginal contribution of the utility to the manager.

2) The manager's marginal utility consists of three parts: the marginal profit fraction contribution of the workers, the bribery and the marginal utility increase or decrease derived from conducting favoritism towards workers.

3) Two variables - the altruistic factor $a$ and the closeness of social ties $\eta$ are introduced to measure the intensity of favoritism, unlike the case where the only variable $\eta$ is parameterized as the intensity of the supervisor's preference for the workers (Prendergast \& Robert H. Topel, 1996 [13]).

This paper discusses the corruptive action widespread in the organizations' worker recruiting: favoritism and bribery. And the main text will be organized with three parts: firstly the brief discussion on the method, secondly the construction of the model and finally the conclusion. The basic logic is that the managers of the firm utilize the information advantage through the two types of misconduct-favoritism and bribery, at the expense of the profit share of the principal (the owner) and the workers' wage rent. The key conclusion is drawn: neither the intensity of favoritism nor the wage level matters in determining whether there's profit or loss in the firm, whereas the key variable is the relative situation of exterior labor market.

\section{Method}

Assume the principal (the only owner of the firm) delegates the labor recruiting to the only manager. The manager can discern the capability (productivity) $c$ of candidates one by one for sure. He is a selfish "altruist", meaning that he receives the bribery and conducts favoritism merely to increase his own utility and finally maximizes his own total utility at the expense of the owner's profit share and the workers' wage rent. Assume the owner of the firm only knows that the social ties with the manager $\eta$ and the capabilities $c$ in terms of the 
monetary value produced by the workers specifically in the firm if they are employed, distribute continuously and uniformly on the rectangular $[-1,1] \times[0,+\infty)$, with the presumption that $\eta$ is independent of $c$. Unlike the manager, the owner is not able to discern the capability and social ties between the manager and the workers one by one. For specialization and information asymmetry, the owner has to delegate the hiring to the manager as well as other routine operations of the firm, and he designs the linear contract for the remuneration of the manager as $\alpha \pi+\beta$, where $\pi$ is the firm's profit and both $\alpha$ and $\beta$ are constants. Even under the positive incentive of hiring highly productive workers to make positive marginal profit for the firm, the manager will still conduct the favoritism (positive or negative) and receive the bribery from candidates to absorb some low productive candidates who make negative marginal profit, since the combination of the two types of activities increase his utility. Most important of all, the owner knows exactly that the manager will conduct the two types of activities unfavorable to him for sure, and the game between them is only one-shot and what' more, he has no way to prevent the manager from conducting them for the owner's lack of specialization and information on the capabilities of workers. To emphasize the importance of incentive, this paper mainly discusses the role of $\alpha$, while mentioning the $\beta$ lightly. To characterize the intensity of favoritism or altruism, the altruistic factor $a \in[0,+\infty)$ has been introduced, and the larger it is, the higher will the intensity be. Besides, the workers willing to be hired by the firm are those who otherwise get paid less. Suppose the workers with capability $c$ can get paid $q c$ at most outside the firm in the labor market, which is independent of the $\eta$-the social ties of workers with the present firm's manager. Since the capability $c$ is specific to the firm mentioned above and $\eta$ is embedded in the relationship between the workers and manager, it's reasonable to assume that $q \in(0,1)$, for the firm could never get positive profit if $q \geq 1$. Here $q$ is a constant determined by the situation of the labor market outside the firm. Smaller $q$ means worse situation of exterior labor market condition and higher probability of getting job in the firm and larger rent size of employment finally deprived totally by the manager as the bribery. Now assume the wage level $w$ is unified across employees to follow the so called principle "Equal pay for equal work", determined by integrating various factors (actually, whether the profit will be positive or negative is independent of the level of $w$, as analyzed later in part 3 of the paper. Thus, analysis on the determination of $w$ is unnecessary for obtaining only the sign of the firm's profit). For simplicity, assume that the total wage amount is bound by the financial constraint of the firm.

Among the three parties-the owner, the manager and the workers searching job in the firm, the manager is the most active player of them, thus, the model should start from the maximization of the manager's utility under the constraint of the owner and workers.

\section{Construction of the Model}

Suppose that the preference of the manager is separable and additive and he is risk neutral. As is mentioned above, the manager's marginal utility which is defined as the second order mixed derivatives of the total utility with respect to the social ties $\eta$ and the capabilities $c$, i.e., $M U=\partial^{2} U /(\partial \eta \partial c)$ which consists of three parts: $\alpha$ fraction of marginal profit, marginal bribery amount and marginal utility derived from his positive or negative favoritism towards workers chosen into the firm by him. Thus his marginal utility can be formulated as

$$
M U=\alpha(c-w)+b+a \eta(w-b)=\alpha(c-w)+a \eta w+(1-a \eta) b
$$

Here the capability $c$ and wage $w$ can be regarded as the present value just at the date of contracting between the manager and the owner, the time preference has not been taken into consideration, i.e., the utility discount factor is assumed to be 1 .

For the workers with capability $c$, had he been employed outside the firm, he would have been paid at most $q c$, thus the inequality $q c \leq w$ must hold. Here the worker is assumed to choose the firm if he gets paid more in the firm or the same as outside, and he will get the wage rent $w-q c$ from the manager, who will accordingly charge the worker as much as possible if only this conduct increase his utility. Now denote the amount of bribery by $b$, then for the rationality of the workers, the inequality $b \leq w-q c$ must hold. If $(1-a \eta)<0$, then the manager will not receive the workers' bribery since doing so decreases the manager's marginal utility and finally decreases his total utility, otherwise he will rationally receive the bribery amount $b=w-q c$ from the workers with capability $c$, since it maximizes both his marginal utility for any worker he employs with bribery and expands the set of employed workers contributing nonnegative marginal utility to him and finally increases his 
total utility.

Then the above marginal utility function in Equation (1) can be rewritten as

$$
M U=\alpha(c-w)+a \eta w+\operatorname{Max}\{(1-\alpha \eta), 0\}(w-q c) \text { for } 0 \leq q c \leq w
$$

For $a<1, a \eta \leq 1$ always holds since $\eta \in[-1,1]$.

The owner's decision is to choose a proper incentive factor $\alpha$ to maximize his residue- the $1-\alpha$ fraction of the firm's profit. What complicates the contract is that the manager is strongly motivated to make profit loss to increase his own total utility by receiving bribery and favoring the preferred workers and recruiting the low productive workers whose $c<w$, since the $\alpha$ fraction of the profit is only a part of his total utility. The owner can increase $\alpha$ to give the manager stronger incentive, which will decrease the owner's fraction of the profit. Moreover, the two types of misconduct of the manager may cause the total profit to be negative, thus the sign of the profit of the firm must be firstly considered. But for $\alpha \in[0,1)$, the sign of residual of the owner is the same as that of the total profit, therefore the sign of the profit and residual can be considered simultaneously for $\alpha \in[0,1)$.

For a given $\alpha \in[0,1)$ chosen by the owner, the manager will select from the rectangular $[-1,1] \times[0,+\infty)$ the workers making his marginal utility nonnegative. Denote the set of the selected workers by $\Omega$, then

$$
\Omega=\{(\eta, c) \mid-1 \leq \eta \leq 1,0 \leq q c \leq w, \alpha(c-w)+b+a \eta(w-b) \geq 0\},
$$

i.e.,

$$
\Omega=\{(\eta, c) \mid-1 \leq \eta \leq 1,0 \leq q c \leq w\} \cap\{(\eta, c) \mid c \geq 0, \alpha(c-w)+a \eta w+\max \{(1-a \eta), 0\} \times(w-q c) \geq 0\}
$$

Now denote the set on the left of the " $\cap$ ” by $R$-the rectangular and the right set by $H$-whose upper left boundary is the left upper part of the hyperbola, then by Equation (3)

$$
\Omega=R \cap H .
$$

The workers in the set $\Omega$ will be chosen by the manager. Moreover, the incentive factor $\alpha$ chosen by the owner, the altruistic factor $a$ and the parameter $q$ will also influence $\Omega$, which determines who will be hired and what amount of bribery must be paid to the manager. The key of classification of $\Omega$ is the positional relation of the hyperbola and the rectangular.

Denote the residual of the owner by $S(\alpha)$, then

$$
S(\alpha)=(1-\alpha) \pi \text {. }
$$

Before classifying $\Omega$ and corresponding residual function of the owner according to the value of $a$ and $q$, it's necessary to propose and prove the following lemma.

Lemma 1. Suppose that $x>0, y>0$.

If $1 \leq x \leq y$ or $y \leq x \leq 1$, then

$$
\ln \frac{x}{y}+\frac{1}{x}-\frac{1}{y} \leq 0
$$

If $x \leq \min \{y, 1\}$ or $x \geq \max \{y, 1\}$, then

$$
\ln \frac{x}{y}+\frac{1}{x}-\frac{1}{y} \geq 0
$$

Proof. Denote $\theta=\frac{x}{y}$, and $\ln \frac{x}{y}+\frac{1}{x}-\frac{1}{y}=\ln \theta+\frac{1}{y}\left(\frac{1}{\theta}-1\right) \stackrel{\Lambda}{=} G(\theta)$, then

$$
\begin{gathered}
G(1)=0, \\
G^{\prime}(\theta)=\frac{1}{\theta}\left(1-\frac{1}{x}\right) .
\end{gathered}
$$

Thus 


$$
\begin{aligned}
& G^{\prime}(\theta)>0 \text { for } x>1, \\
& G^{\prime}(\theta)=0 \text { for } x=1 \\
& \text { and } \\
& G^{\prime}(\theta)<0 \text { for } x<1 .
\end{aligned}
$$

Finally Equation (6) and Equation (7) are obtained. Q.E.D.

Now classify $\Omega$ according to the value of $a$ and then reclassify the subclass according to the value of $q$.

1) If $a=0$, then reclassify $q$ into the two subclasses: $q \in\left(0, \frac{1}{2}\right]$ and $q \in\left(\frac{1}{2}, 1\right)$, and it follows that

$$
M U=\alpha(c-w)+a \eta w+\operatorname{Max}\{(1-a \eta), 0\}(w-q c)=\alpha(c-w)+(w-q c) \text { if } \alpha \geq q,
$$

Then $M U \geq 0$ holds for any $(\eta, c) \in R$;

If $\alpha<q, \quad M U \geq 0 \Leftrightarrow c \leq \min \left\{\frac{w}{q}, \frac{1-\alpha}{q-\alpha} w\right\}=\frac{w}{q}$, then $M U \geq 0$ holds for any $(\eta, c) \in R$ thus $a=0$ causes $R \subset H$ and $\Omega=R \cap H=R$,

$$
S(\alpha)=(1-\alpha) \int_{\Omega}(c-w) \mathrm{d} c \mathrm{~d} \eta=(1-\alpha) \int_{-1}^{1} \int_{0}^{w / q}(c-w) \mathrm{d} c \mathrm{~d} \eta=(1-\alpha) w^{2}\left(1 / q^{2}-2 / q\right), \quad \alpha \in[0,1)
$$

It follows that:

$$
\begin{aligned}
& \text { If } q \in\left(0, \frac{1}{2}\right] \text {, then } S(\alpha) \geq 0 \\
& \text { If } q \in\left(\frac{1}{2}, 1\right) \text {, then } S(\alpha)<0
\end{aligned}
$$

2) If $a \rightarrow \infty$, then reclassify $q$ into the two subclasses: $q \in\left(0, \frac{1}{2}\right]$ and $q \in\left(\frac{1}{2}, 1\right)$, and it follows that

For any $\eta<0$ and $c>0 \quad a \eta q c \rightarrow-\infty$, thus for any $\eta<0$ and $c>0 \quad(\eta, c) \notin H$, and $(\eta, c) \notin \Omega$.

But for $\eta \in[0,1]$ and $c \geq 0$, or $\eta<0$ and $c=0,(\eta, c) \in H$, thus

$$
\begin{gathered}
\Omega=\left\{(\eta, c) \mid \eta \geq 0,0 \leq c \leq \frac{w}{q}\right\} \cup\{(\eta, c) \mid \eta<0, c=0\} \\
S(\alpha)=(1-\alpha) \int_{\Omega}(c-w) \mathrm{d} c \mathrm{~d} \eta=(1-\alpha) \int_{0}^{1} \int_{0}^{w / q}(c-w) \mathrm{d} c \mathrm{~d} \eta=(1-\alpha) w^{2}\left(1 / q^{2}-2 / q\right) / 2, \quad \alpha \in[0,1]
\end{gathered}
$$

It follows that:

$$
\begin{aligned}
& \text { If } q \in\left(0, \frac{1}{2}\right] \text {, then } S(\alpha) \geq 0 \\
& \text { If } q \in\left(\frac{1}{2}, 1\right) \text {, then } S(\alpha)<0
\end{aligned}
$$

3) If $a \in(0,1]$, then consider the left upper boundary of $H: \partial H=\{(\eta, c) \mid c \geq 0,(\alpha-q+a q \eta) c=(\alpha-1) w\}$, then reclassify $q$ by the positional relation of $\partial H$ and $R$. Now consider the intersection of $\partial H$ and the upper boundary of $R$. The intersection is the only point $\left(-\frac{\alpha}{a}\left(\frac{1}{q}-1\right), \frac{w}{q}\right)$, then, obviously the inequality $\eta_{*}=-\frac{\alpha}{a}\left(\frac{1}{q}-1\right) \leq 0$ always holds (here $-\frac{\alpha}{a}\left(\frac{1}{q}-1\right)$ is denoted by $\eta_{*}$ ). But it's possible that $\eta_{*} \leq-1$, which means that all of the workers in the set $R$ will be hired by the manager, the same as $a=0$. To make $\eta_{*} \leq-1$ possible, it must be $-\frac{1}{a}\left(\frac{1}{q}-1\right) \leq-1 \Leftrightarrow q \leq \frac{1}{1+a}$, since $\alpha \in[0,1]$, thus reclassify $q$ into the following three 
subclasses: $q \in\left(0, \frac{1}{2}\right), \quad q \in\left(\frac{1}{2}, \frac{1}{1+a}\right)$ and $q \in\left(\frac{1}{1+a}, 1\right)$.

a) For $q \in\left(0, \frac{1}{2}\right], \quad q \leq \frac{1}{1+a}$ holds, and if

$$
\alpha>\frac{a q}{1-q},
$$

then $\eta_{*}=\frac{\alpha}{a}\left(1-\frac{1}{q}\right) \leq-1$, thus

$$
S(\alpha)=(1-\alpha) w^{2}\left(1 / q^{2}-2 / q\right) \geq 0 .
$$

But if $\alpha \leq \frac{a q}{1-q}$, then

$$
\begin{aligned}
S(\alpha)= & (1-\alpha) \int_{-1}^{\frac{\alpha}{a}\left(1-\frac{1}{q}\right)} \int_{0}^{\frac{(\alpha-1) w}{\alpha-q+a q \eta}}(c-w) \mathrm{d} c \mathrm{~d} \eta+(1-\alpha) \int_{\frac{\alpha}{a}}^{1}\left(1-\frac{1}{q}\right) \int_{0}^{\frac{w}{q}}(c-w) \mathrm{d} c \mathrm{~d} \eta \\
= & \frac{w^{2}(1-\alpha)^{3}}{2 a q}\left[\frac{1}{\alpha-q-a q}+\frac{1}{q(1-\alpha)}\right]+\frac{w^{2}(1-\alpha)^{2}}{a q} \ln \left(\frac{(1-\alpha) q}{(1+a) q-\alpha}\right) \\
& +\frac{w^{2}(1-\alpha)}{2}\left[\left(\frac{1}{q}-1\right)^{2}-1\right]\left[1+\frac{\alpha}{a}\left(\frac{1}{q}-1\right)\right]
\end{aligned}
$$

Denote

$$
\begin{gathered}
M=\frac{w^{2}(1-\alpha)}{2}\left[\left(\frac{1}{q}-1\right)^{2}-1\right]\left[1+\frac{\alpha}{a}\left(\frac{1}{q}-1\right)\right], \\
N=\frac{w^{2}(1-\alpha)^{3}}{2 a q}\left[\frac{1}{\alpha-q-a q}+\frac{1}{q(1-\alpha)}\right]+\frac{w^{2}(1-\alpha)^{2}}{a q} \ln \left(\frac{(1-\alpha) q}{(1+a) q-\alpha}\right) \\
=\frac{w^{2}(1-\alpha)^{2}}{a q}\left[\frac{1}{2 q}-\frac{1}{2[(1+a) q-\alpha] /(1-\alpha)}\right]+\frac{w^{2}(1-\alpha)^{2}}{a q} \ln \left(\frac{2 q}{2[(1+a) q-\alpha] /(1-\alpha)}\right),
\end{gathered}
$$

then $M>0$ as $q \in\left(0, \frac{1}{2}\right]$. Let $x=2 q, \quad y=\frac{2[(1+a) q-\alpha]}{1-\alpha}$ as $q \in\left(\frac{1}{2}, \frac{1}{1+a}\right)$, then $x \leq 1$. Since

$$
q<\frac{1}{1+a} \Leftrightarrow \frac{a q}{1-q}>1
$$

then $\alpha<\frac{a q}{1-q}$ must hold, then

$$
(1-\alpha) q-[(1+a) q-\alpha]=(1-q)\left[\alpha-\frac{a q}{1-q}\right] \leq 0,
$$

which means $x \leq y$, then $x \leq \min \{y, 1\}$. By Lemma 1, since $N \geq 0$ always holds, then by Equation (15)

$$
S(\alpha)=M+N \geq 0
$$

b) For $q \in\left(\frac{1}{2}, \frac{1}{1+a}\right)$, then $x>1$ and $M<0$. 
If $\alpha \leq \frac{a q}{1-q}$, then

$$
(1-\alpha) q-[(1+a) q-\alpha]=(1-q)\left[\alpha-\frac{a q}{1-q}\right]<0 \Rightarrow x<y
$$

i.e.

$$
1<x<y \text {. }
$$

Then by Lemma 1,

$$
N=\frac{w^{2}(1-\alpha)^{2}}{a q}\left[\ln \frac{x}{y}+\frac{1}{x}-\frac{1}{y}\right]<0,
$$

thus

$$
S(\alpha)=M+N<0
$$

But if $\alpha>\frac{a q}{1-q}$, then

$$
S(\alpha)=(1-\alpha) w^{2}\left(1 / q^{2}-2 / q\right)<0
$$

For c) $q \in\left(\frac{1}{1+a}, 1\right)$, then $x>1$ and $M<0$, since it can only be $\alpha \leq \frac{a q}{1-q}$, then

$$
(1-\alpha) q-[(1+a) q-\alpha]=(1-q)\left[\alpha-\frac{a q}{1-q}\right]<0 \Rightarrow x<y,
$$

i.e.

$$
1<x<y
$$

By Lemma 1,

$$
N=\frac{w^{2}(1-\alpha)^{2}}{a q}\left[\ln \frac{x}{y}+\frac{1}{x}-\frac{1}{y}\right]<0 .
$$

Then we get

$$
S(\alpha)=M+N<0 .
$$

4) $a \in(1,+\infty)$, similar to case 3) reclassify $q: q \in\left(0, \frac{1}{1+a}\right), q \in\left[\frac{1}{1+a}, \frac{1}{2}\right]$, and $q \in\left(\frac{1}{2}, 1\right)$.

a) For $q \in\left(0, \frac{1}{1+a}\right)$, as is analyzed in case 3), $q \in\left(0, \frac{1}{1+a}\right) \subset\left(0, \frac{1}{2}\right)$, then $M>0$.

If $\alpha>\frac{a q}{1-q}$, then

$$
S(\alpha)=(1-\alpha) w^{2}\left(1 / q^{2}-2 / q\right)>0 .
$$

If $\alpha \leq \frac{a q}{1-q}$, then $N>0$ and finally

$$
S(\alpha)=M+N>0 .
$$

b) For $q \in\left[\frac{1}{1+a}, \frac{1}{2}\right]$, it follows that $\alpha \leq \frac{a q}{1-q}$, similar to a), there must be 


$$
S(\alpha)=M+N \geq 0
$$

c) For $q \in\left(\frac{1}{2}, 1\right)$, it can only be $\alpha \leq \frac{a q}{1-q}$, then $M<0$ and $N<0$ as in case 3).

$$
S(\alpha)=M+N<0 .
$$

Based on Equations (9)-(23) except (11) and (15), it is not difficult to generalize the results as the following proposition.

Proposition. Whenever the owner can't prevent the manager from conducting favoritism and receiving bribery from workers, it follows that

1) If $q>1 / 2$, the firm will encounter negative profit for any $\alpha \in[0,1)$ and any $a \in[0,+\infty)$.

2) If $q<1 / 2$, the firm will make positive profit for any $\alpha \in[0,1)$ and any $a \in[0,+\infty)$.

3) If $q=1 / 2$, the firm will make zero profit for any $\alpha$ satisfying $\alpha \geq a$ and negative profit for any $\alpha$ satisfying $\alpha<a$.

The intuition behind the proposition is not always clear. In the case of $\alpha>\frac{a q}{1-q}$, i.e. the intersection of the rectangular $R$ and the half hyperbola $\partial H$ is empty, then it's quite intuitive that the profit is negative whenever $q>1 / 2$ since the workers with low productivity $(c<w)$ outweigh those with high productivity $(c>w)$, thus the loss made by the former exceeds the profit made by the latter. But in the case of $\alpha<\frac{a q}{1-q}, \partial H \cap R \neq \Phi$, the same results is not so intuitive. As the manager rejects the most productive (whose $c$ are close to or equal to $w / q$ ) and also most disliked workers (whose $\eta$ are close to or equal -1 ), then the loss incurred by the low productive workers exceeds the profit made by those with high productivity, because the most productive workers are only willing to pay a smaller amount of bribery to the manager since they get smaller amount of wage rent before bribery as $w-q c$ is smaller since $c$ is larger. The exclusion of the most productive and also the most disliked workers causes the net loss of the firm, which makes the pure incentive contract $(\beta=0)$ fails. Then it's proper to set $\alpha=1$ and $\beta<0$, but what level of $\beta$ is optimal? It depends on a lot of variables, such as the reserve utility of the manager, the financial constraint, which, combined with other factors, determines the wage level of workers. The residual is always proportional to the square of wage level, thus the sign of the residual is unrelated to the wage level, for the reason that the wage rent has been fully deprived of by the manager, thus their actual wage is the same as that in exterior labor market only if the workers' $\eta \leq 1 / a$. As for the workers with $\eta>1 / a$, the profit made by them is also proportional to the square of wage level. The sign of the residual is also unrelated to the value of $a$-the intensity of favoritism for the same reason as mentioned above.

In the case of $q<1 / 2$, the profit is always positive, which is of some practical importance. As the indicator of the exterior condition of labor market, smaller $q$ means the stagnation of exterior labor market, thus many workers, even if they are highly productive, still have great difficulty in finding high-waged jobs through regular tunnels in exterior market, thus they are driven to seize higher waged job from the firm. However, all of the hired workers but those whose $\eta \geq 1 / a$ are deprived of the wage rent by the manager, whereas the manager still makes positive net profit for the owner because there are large enough proportion of highly productive workers offsetting the loss incurred by low productive workers. Evidence shows that in recent years, private sectors, including many foreign-funded firms in China have reduced positions and the wage of workers, then it's more difficult for them to find a highly paid job, thus the bribery and use of Guanxi to seize the position in state-owned enterprise and government is widespread, for the unsolved obstacle to prevent the responsible personnel in the public sector from conducting bribery and Guanxi (Tong Jun Wang et al., 2014).

The positive profit of state-owned enterprises caused by small $q$ may conceal the corruption in the process of hiring workers, but as exterior labor market boom, i.e., $q$ increase, workers with highest productivity tend to find job directly in the labor market since they are paid more, while the workers with low productivity tend to use bribery and the Guanxi to get employed in the public sector, finally, big loss will appear and the corruption hidden in the boom will be exposed. However, in the market monopolized by the state owned enterprises, the enterprises can increase the price of its product and therefore decrease the level of $q$ to earn positive profit, for the productivity $c$ is measured in terms of the monetary value produced by each worker. As a result, the situation of making profit or loss can't be altered by merely changing the wage level or reassign the manager with different 
intensity of favoritism, since the sign of the residual is unrelated to the wage level and intensity of favoritism $a$. Thus the usual resort to make up the deficits and get surpluses by the state owned enterprises is to increase the output price.

When $q<1 / 2$, the positive profit makes sense the sharing of itself among the manager and the owner, thus the optimal incentive factor $\alpha$ should be determined. The existence of optimal $\alpha$ to maximize the residual of the owner can be verified since the residual function $S(\alpha)$ is continuous with respect to $\alpha \in[0,1]$ and the domain of it is compact.

Generally, it's difficult to use the traditional first order condition to determine the optimal $\alpha$ for the intricacy of the residual function $S(\alpha)$, thus using numerical method with mathematical software may help. It's not easy to discuss the variation of the residual or profit with respect to $a$ or $q$ since they influence not only the value of the marginal utility of the manager, but also the set of workers being hired

\section{Conclusion and Possible Extension}

The simplified model in this article characterizes the games among the explicit three parties in the process of recruiting. In the game, the principal (the owner of the firm) is informed of the distribution of workers' productivity and social ties with the manager and exterior condition of the labor market. He is also aware of the intensity of the manager's favoritism toward workers, but he can't discern the workers one by one in terms of productivity and their Guanxi with the manager. The manager is assumed to be fully informed of the condition of the workers and the situation of exterior labor market, and what's more, he possesses the talent for recruiting the workers, and thus he can utilize the advantage of information and specialization to serve his interest at the expense of the owner's profit fraction and the worker's wage rent. The workers are most passive among the three parties, and they can only choose to be hired or not. Their wage rent is fully deprived, if the favoritism received from the manager is small enough.

Besides the third explicit parties involving in the recruiting, the implicit party-the exterior labor market plays the key role in the decision and interest of the manager and the owner, and the fate of the incentive contract. As for monopoly firms, the managers are able to increase the price level of its output to comparatively worsen the situation of the exterior labor market to attract enough numbers of highly productive workers to hedge the loss incurred by low productive workers who enjoy social ties with the manager and pay the corresponding bribery with the amount just equal to their wage rent. The key conclusion in this article is that it's just the $q$, which measures the related situation of exterior labor market, determining whether the firm makes positive or negative profit, not the wage level or the intensity of favoritism of the manager, for they only impact the absolute value of the profit or loss.

The article starts from the analysis of the model from the marginal utility and then determines the set of workers to be hired and corresponding bribery amount, unlike most other models starting from the function of total utility of the agent with constraint independent of the preference. The target function has great difficulty in further analysis, but through the lemma, the most important qualitative result has been obtained. The main obstacle to further analysis is mathematical. In fact, many aspects, such as randomization of the manager's intensity of favoritism, the possible prevention of bribery or favoritism, comparison of results with those without bribery, multi-period consideration and reputation of the manager, may be incorporated into the model. However, any direction of the extension will complicate the models and cause it tougher.

\section{References}

[1] Williamson, O., Wachter, M. and Harris, M. (1975) Understanding the Employment Relation: An Analysis of Idiosyncratic Exchange. Bell Journal of Economics, 6, 250-278. http://dx.doi.org/10.2307/3003224

[2] Greenwald, B.C. (1986) Adverse Selection in the Labor Market. Review of Economic Studies, 53, 325-347. http://dx.doi.org/10.2307/2297632

[3] Spencd, A.M. (1974) Job Market Signaling. Quarterly Journal of Economics, 87, 355-374.

[4] Breaugh, J.A. and Starke, M. (2000) Research on Employee Recruitment: So Many Remaining Questions. Journal of Management, 26, 405-434. http://dx.doi.org/10.1177/014920630002600303

[5] Grannovetter, M. (1988) The Sociological and Economic Approaches to Labor Market Analysis: A Social Structural View. In: Farkas, G. and England, P., Eds., Industries, Firms and Jobs: Sociological and Economic Approaches, Plenum Press, New York, 187-216. http://dx.doi.org/10.1007/978-1-4899-3536-6_9 
[6] Montgomery, J. (1991) Social Networks and Labor Market Outcomes: Towards an Economic Analysis. American Economic Review, 81, 1408-1418.

[7] Ioannides, M. and Loury, L. (2004) Job Information Networks, Neighborhood Effects, and Inequality. Journal of Economic Literature, 42, 1056-1093. http://dx.doi.org/10.1257/0022051043004595

[8] Goldberg, M. (1982) Discrimination, Nepotism, and Long-Run Wage Differentials. Quarterly Journal of Economics, 2, 307-319. http://dx.doi.org/10.2307/1880760

[9] Wang, T.J., Si, J.W. and Duan, G.H. (2014) Relationships among Undergraduates' Occupation Attributional Style, Work Values, Career Decision Making Self-Efficacy and Job Searching. International Conference on Global Economy, Finance and Humanities Research (GEFHR 2014).

[10] Obukhova, E. (2012) Motivation vs. Relevance: Using Strong Ties to Find a Job in Urban China. Social Science Research, 41, 570-580. http://dx.doi.org/10.1016/j.ssresearch.2011.12.010

[11] Carmichael, H.L. (1988) Incentives in Academics: Why Is There Tenure? Journal of Political Economy, 96, $453-472$. http://dx.doi.org/10.1086/261547

[12] Friebel, G. and Raith, M. (2004) Abuse of Authority and Hierarchical Communication. Rand Journal of Economics, 35, 224-244. http://dx.doi.org/10.2307/1593689

[13] Prendergast, C. and Topel, R. (1996) Favoritism in Organizations. Journal of Political Economy, 104, 958-978. http://dx.doi.org/10.1086/262048

[14] Levine, D.K., Weinschelbaum, F. and Zurita, F. (2010) The Brother in Law Effect. International Economic Review, 51, 497-507. http://dx.doi.org/10.1111/j.1468-2354.2010.00590.x

[15] Bramoullé, Y. and Goyal, S. (2009) Favoritism. Cahier de recherché. Working Paper 09-41, CIRPéE.

[16] Ponzo, M. and Scoppa, V. (2011) A Simple Model of Favoritism in Recruitment. Research in Economics, 65, 78-88. http://dx.doi.org/10.1016/j.rie.2010.09.003 